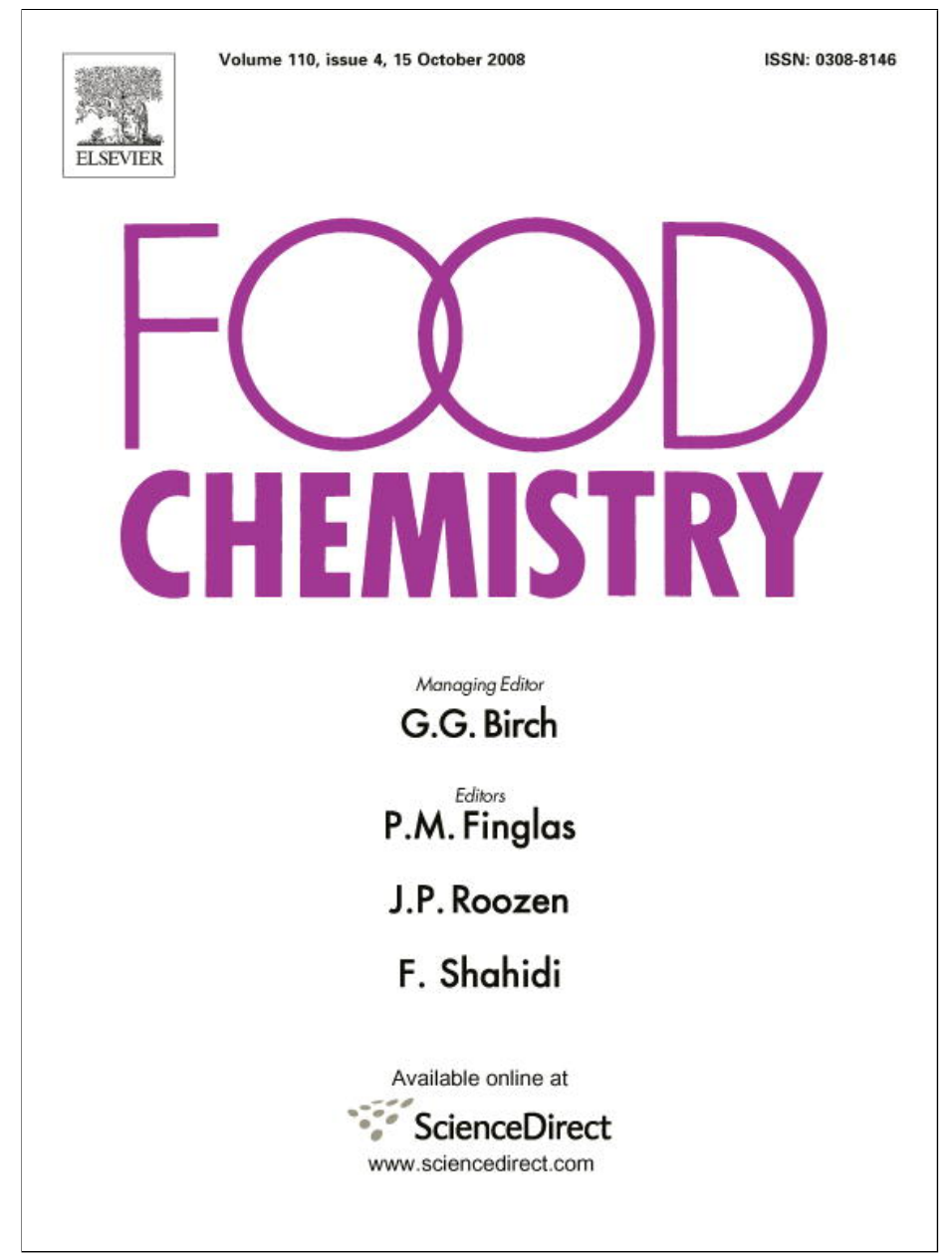

This article appeared in a journal published by Elsevier. The attached copy is furnished to the author for internal non-commercial research and education use, including for instruction at the authors institution and sharing with colleagues.

Other uses, including reproduction and distribution, or selling or licensing copies, or posting to personal, institutional or third party websites are prohibited.

In most cases authors are permitted to post their version of the article (e.g. in Word or Tex form) to their personal website or institutional repository. Authors requiring further information regarding Elsevier's archiving and manuscript policies are encouraged to visit:

http://www.elsevier.com/copyright 
Analytical Methods

\title{
Optimization of the determination of tocopherols in Agaricus sp. edible mushrooms by a normal phase liquid chromatographic method
}

\author{
Lillian Barros $^{\mathrm{a}, \mathrm{b}}$, Daniela M. Correia ${ }^{\mathrm{a}}$, Isabel C.F.R. Ferreira ${ }^{\mathrm{a}, *}$, Paula Baptista ${ }^{\mathrm{a}}$, Celestino Santos-Buelga ${ }^{\mathrm{b}}$ \\ ${ }^{a}$ CIMO-Escola Superior Agrária, Instituto Politécnico de Bragança, Campus de Sta. Apolónia, Apartado 1172, 5301-855 Bragança, Portugal \\ ${ }^{\mathrm{b}}$ Unidad de Nutrición y Bromatología, Facultad de Farmacia, Universidad de Salamanca, Campus Miguel de Unamuno s/n, E-37007 Salamanca, Spain
}

\section{A R T I C L E I N F O}

\section{Article history:}

Received 31 October 2007

Received in revised form 3 March 2008

Accepted 4 March 2008

\section{Keywords:}

Vitamin E

HPLC

Analysis

Mushrooms

\begin{abstract}
A B S T R A C T
Individual tocopherol profile of five Agaricus mushroom species, widely consumed in Portugal, was obtained by a normal-phase high-performance liquid chromatography (NP-HPLC). It was used a simple solid-liquid extraction procedure without saponification step and the chromatographic separation was achieved using a YMC-Pack Polyamine II column using an isocratic elution with hexane/ethyl acetate $(70: 30, v / v)$ at a flow rate of $1.0 \mathrm{~mL} / \mathrm{min}$. The effluent was monitored by a fluorescence detector. All the compounds were separated in a period of time of $30 \mathrm{~min}$. The method proved to be sensitive, reproducible and accurate, allowing the determination of tocopherols.
\end{abstract}

(c) 2008 Elsevier Ltd. All rights reserved.

\section{Introduction}

Tocopherols and tocotrienols are known under the generic name vitamin E, and the chemical name tocochromanols. Tocopherols (Fig. 1) are methyl-substituted hydroxychromans with a polar chromanol ring and an apolar phytyl side chain (Kamal-Eldin \& Appelqvist, 1996). There are four tocopherol vitamers $(\alpha-, \beta-, \gamma-$ and $\delta$-tocopherol) which can be distinguished by the number and location of methyl groups on their chromanol ring (Ryynanen, Lampi, Salo-Vaananen, Ollilainen, \& Piironen, 2007). For healthy people it is relatively easy to obtain sufficient tocopherols and tocotrienols from the diet to prevent well-defined vitamin E deficiency symptoms. Most plant-derived foods, especially fruits and vegetables, contain low to moderate levels of vitamin E activity; but, due to the abundance of plant-derived foods in our diets, they provide a significant and consistent source of vitamin $\mathrm{E}$ (Chun, Lee, Ye, Exler, \& Eitenmiller, 2006). Furthermore, high intakes of E vitamers may decrease the risk of several chronic diseases related to oxidative damage, e.g., coronary heart diseases and cancer. Most of these effects (in the human body) are associated to their action as lipid-soluble antioxidants (Schwenke, 2002; Stampfer \& Rimm, 1995; Stone \& Papas, 1997; Theriault, Chao, Wang, Gapor, \& Adeli, 1999). The biological activities of these compounds are mainly attributed to their antioxidant activity in inhibiting lipid peroxidation in biological membranes. They act as antioxidant by donating a hydrogen atom to peroxyl radicals of unsaturated lipid mole-

\footnotetext{
* Corresponding author. Tel.: +351 273303219; fax: +351 273325405.

E-mail address: iferreira@ipb.pt (I.C.F.R. Ferreira).
}

cules, forming a hydroperoxide and a tocopheroxyl radical, which reacts with other peroxyl or tocopheroxyl radicals forming more stable adducts (Lampi, Kataja, Kamal-Eldin, \& Piironen, 1999). In fact, vitamin E plays a fundamental role in the prevention of radical formation in biological systems like plasma, membranes, tissues, and in the free radical chain reactions interruption (Sanagi, See, Ibrahim, \& Naim, 2005).

In the past, $\alpha$-tocopherol was the most studied vitamer and it was reported to exhibit the highest biological activity. Thus, several methods were developed exclusively for the determination of this compound. However, many studies focusing on the health effects of the other vitamin $\mathrm{E}$ isoforms have been published (Campbell, Stone, Whaley, \& Krishnan, 2003; Mishima et al., 2003).

There is a growing interest in natural antioxidants for their potential role in the prevention of oxidative stress-related diseases, since synthetic antioxidants are being questioned due to their potential carcinogenic activity (Fukushima \& Tsuda, 1985). Therefore, natural antioxidants such as tocopherol, polyphenols and carotenoid pigments are having a greater relevance in the protection against lipid oxidation.

The use of mushrooms extracts as antioxidants is becoming increasingly popular (Barros, Baptista, Correia, Morais, \& Ferreira, 2007; Barros, Baptista, \& Ferreira, 2007; Barros, Ferreira, Queirós, Ferreira, \& Baptista, 2007; Ferreira, Baptista, Vilas-Boas, \& Barros, 2007; Lo \& Cheung, 2005; Turkoglu, Duru, Mercan, Kivrak, \& Gezer, 2007) and could bring diverse physiological benefits to the consumer, such as protection against human diseases associated with oxidative stress, like coronary heart disease and cancer (Halliwell \& Gutteridge, 1999; Lindequist, Niedermeyer, \& Julich, 2005). 


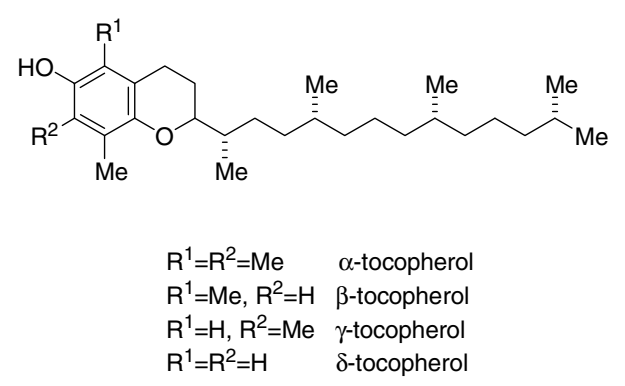

Fig. 1. Chemical structures of the four tocopherol isomers.

Accordingly, there is a great need for an efficient technique for separating and quantifying the individual antioxidant components such as tocopherols. Although various reports have been published on the tocopherols content of mushrooms (Elmastas, Isildak, Turkekul, \& Temur, 2007; Mau, Lin, \& Chen, 2002; Mau, Lin, \& Song, 2002; Tsai, Tsai, \& Mau, 2007; Yang, Lin, \& Mau, 2002), all reported the same methodology including saponification and do not present validation assays. In this study, we selected an extraction method which did not include saponification, and used an antioxidant to avoid tocopherols oxidation, with special precautions to protect the samples from light and heat. The accuracy, precision and robustness of the method were improved by incorporating an internal standard (IS) from the extraction step through to the chromatographic analysis. As well, the use of fluorescence rather than UV as the detection mode provided the sensitivity and the selectivity required for the accurate determination of low levels of these homologues in mushrooms.

\section{Materials and methods}

\subsection{Standards and reagents}

Tocopherol standards ( $\alpha, \beta, \gamma$ and $\delta$ ) were purchased from Sigma (St. Louis, MO). Butylated hydroxytoluene (BHT) was obtained from Merck (Darmstadt, Germany), n-hexane 95\% and ethyl acetate 99.8\% were of HPLC grade from Lab-Scan (Lisbon, Portugal). All other reagents were of analytical grade.

\subsection{Preparation of standard solutions}

Individual stock solutions ( $\sim 5 \mathrm{mg} / \mathrm{mL})$ of $\alpha$-, $\beta$-, and $\gamma$-tocopherols were prepared in hexane and stored protected from light, at $-20^{\circ} \mathrm{C}$. A stock standard mixture with the three isomers was prepared in hexane with the final concentration of $1 \mathrm{mg} / \mathrm{mL}$ for each isomer. Working standard mixture with concentration of $10 \mu \mathrm{g} / \mathrm{mL}$ was prepared from the stock standard solution. $\delta$-Tocopherol was used as internal standard (IS), being prepared a stock solution at $50 \mu \mathrm{g} / \mathrm{mL}$ in hexane, kept at $-20^{\circ} \mathrm{C}$, protected from light, and diluted to a working solution $(1.6 \mu \mathrm{g} / \mathrm{mL})$. BHT was prepared in hexane at a concentration of $10 \mathrm{mg} / \mathrm{mL}$. Fig. 2A shows a chromatogram of a standards mixture.

\subsection{Samples}

Five mushrooms species: Agaricus bisporus (Lange) Imbach, Agaricus arvensis Schaeffer, Agaricus romagnesii Wasser, Agaricus silvaticus Schaeff, and Agaricus silvicola (Vittadini) Peck were analyzed. The first was a commercial sample obtained in a local supermarket and was used during method development and validation procedures. All the others were wild species and were collected under glassland in Bragança (Northeast of Portugal), in autumn 2006. Taxonomic identification was made according to
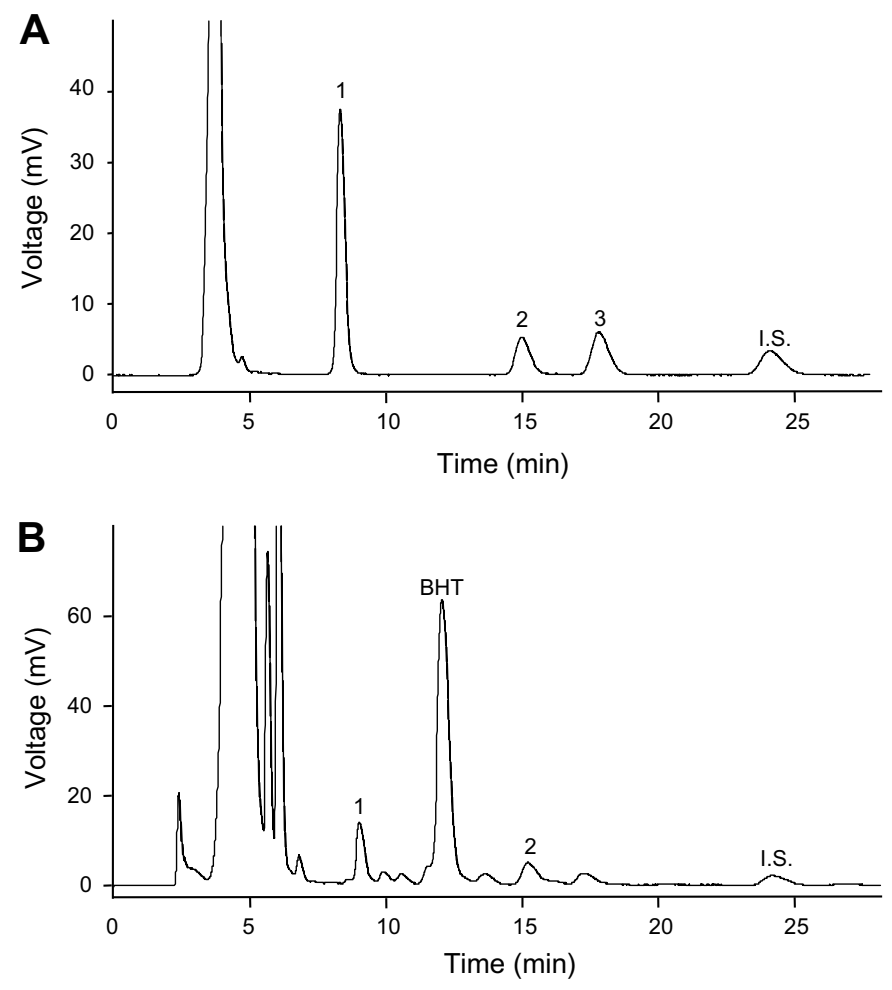

Fig. 2. HPLC fluorescence chromatograms of the working standards mixture (A) and of a mushroom sample extracted using method III (B). Peaks: 1, $\alpha$-tocopherol; 2 , $\beta$-tocopherol; 3, $\gamma$-tocopherol; IS, internal standard ( $\delta$-tocopherol); BHT, butylated hydroxytoluene.

several authors (Courtecuisse \& Duhem, 1995; Moser, 1983) and representative voucher specimens were deposited at the herbarium of Escola Superior Agrária of Instituto Politécnico de Bragança. After collection and taxonomic identification, all the mushrooms were dried in a lyophilizator (Ly-8-FM-ULE, Snijders, HOLLAND) before analysis.

\subsection{Extraction procedure}

BHT solution $(100 \mu \mathrm{L})$ and IS solution $(250 \mu \mathrm{L})$ were added to the sample prior to the extraction procedure. The samples $(\sim 500 \mathrm{mg})$ were homogenized with methanol $(4 \mathrm{~mL})$ by vortex mixing ( $1 \mathrm{~min})$. Subsequently, hexane $(4 \mathrm{~mL})$ was added and again vortex mixed for $1 \mathrm{~min}$. After that, saturated $\mathrm{NaCl}$ aqueous solution $(2 \mathrm{~mL})$ was added, the mixture was homogenized (1 min), centrifuged ( $5 \mathrm{~min}, 4000 \mathrm{~g}$ ) and the clear upper layer was carefully transferred to a vial. The sample was re-extracted twice with hexane. The combined extracts were taken to dryness under a nitrogen stream, redissolved in $1 \mathrm{~mL}$ of $n$-hexane, dehydrated with anhydrous sodium sulphate, filtered through a $0.22 \mu \mathrm{m}$ disposable LC filter disk, transferred into a dark injection vial and analysed by HPLC.

\subsection{HPLC analysis}

The HPLC equipment consisted of an integrated system with a Smartline pump 1000 (Knauer, Germany), a degasser system Smartline manager 5000, an AS-2057 auto-sampler and a 2500 UV detector at $295 \mathrm{~nm}$ (Knauer, Germany) connected in series with a FP-2020 fluorescence detector (Jasco, Japan) programmed for excitation at $290 \mathrm{~nm}$ and emission at $330 \mathrm{~nm}$. Data were analysed using Clarity 2.4 Software (DataApex). The chromatographic separation was achieved with a Polyamide II $(250 \times 4.6 \mathrm{~mm})$ 
normal-phase column from YMC Waters (Japan) operating at $30^{\circ} \mathrm{C}$ (7971 R Grace oven). The mobile phase used was a mixture of $n$-hexane and ethyl acetate $(70: 30, v / v)$ at a flow rate of $1 \mathrm{~mL} /$ min, and the injection volume was $20 \mu \mathrm{L}$. The compounds were identified by chromatographic comparisons with authentic standards. Quantification was based on the fluorescence signal response, using the internal standard method. Tocopherol contents in mushroom samples are expressed in ng per $\mathrm{g}$ of dry mushroom.

\subsection{Validation assays}

The repeatability and reproducibility of the chromatographic method were evaluated using standard solutions of the four vitamers at the concentration levels 80,400 and $800 \mathrm{ng} / \mathrm{mL}$. For the repeatability, the standards solutions were analysed seven times in the same day, while for the reproducibility the standards solutions were analysed three times in five consecutive days.

Also, the precision of the extraction method was validated taking into account their repeatability, reproducibility, precision and accuracy. The repeatability and reproducibility was accomplished using a mushroom sample, A. bisporus, by analysing three times in the same day and in five consecutive days, respectively. Precision was accessed by three extractions of the same mushroom sample being each one analysed in five consecutive days. The accuracy of the method was evaluated by the standard addition procedure (\% of recovery), with three addition levels (80, 400 and $800 \mathrm{ng} / \mathrm{mL}$ ) each one in triplicate. The standards mixture was added to the sample, and all the extraction procedures were carried out.

\subsection{Statistical analysis}

For each one of the Agaricus sp. three samples were analysed and also all the assays were carried out in triplicate. The results are expressed as mean values and standard deviation (SD). The mushrooms tocopherols content was analysed using one-way analysis of variance (ANOVA) followed by Tukey's HSD Test with $\alpha=0.05$. This treatment was carried out using SAS v. 9.1.3 program.

\section{Results and discussion}

\subsection{Chromatographic conditions}

It is know that NP-HPLC (normal-phase) is generally preferred instead of RP-HPLC (reversed-phase) for tocopherols determination since the last system does not completely resolve $\beta$ - and $\gamma$-isomers. Beside, NP-HPLC has the advantage of allowing the use of organic solvents, thus achieving higher lipid solubility and higher loading capacity (Amaral, Casal, Torres, Seabra, \& Oliveira, 2005; Kamal-Eldin, Gorgen, Peterson, \& Lampi, 2000). For the separation of vitamin E isomers, we adopted the YMC-Pack Polyamine II NPcolumn and hexane/ethyl acetate as mobile phase. The coefficients of variation for the retention time achieved in this work were low (less then $0.5 \%$ for all standard compounds) (Table 1 ).

The quantification was performed by the internal standard method in order to improve accuracy, precision and robustness characteristics. The isomer $\delta$-tocopherol was chosen as the internal standard (IS; Fig. 2B) because it was not detected in the analysed mushrooms, as also presented an adequate recovery. The recovery of the IS was obtained dividing the area of $\delta$-tocopherol standard (equivalent to $400 \mathrm{ng} / \mathrm{mL}$ ) by the area of the spiked sample after adding $\delta$-tocopherol to obtain a final concentration of $400 \mathrm{ng} / \mathrm{mL}$. The IS concentration is kept constant in all the analyses. Therefore, the concentration of each tocopherol found in the mushroom samples is obtained using the response factor for each
Table 1

Retention times, linearity and sensitivity of HPLC analysis

\begin{tabular}{|c|c|c|c|c|c|c|}
\hline \multirow[t]{2}{*}{ Standard } & \multicolumn{2}{|c|}{$R_{t}$ (retention time) } & \multirow{2}{*}{$\begin{array}{l}\text { Correlation } \\
\text { coefficient }\left(r^{2}\right)\end{array}$} & \multirow{2}{*}{$\begin{array}{l}\text { Linearity } \\
\text { range } \\
(\mathrm{ng} / \mathrm{mL})\end{array}$} & \multicolumn{2}{|l|}{ Limits } \\
\hline & $\min$ & $\mathrm{CV} \%(n=11)$ & & & $\begin{array}{l}\text { LOD } \\
\text { (ng/mL) }\end{array}$ & $\begin{array}{l}\text { LOQ } \\
(\mathrm{ng} / \mathrm{mL})\end{array}$ \\
\hline$\alpha$-Tocopherol & 8.75 & 0.31 & 0.9999 & $40.0-800.0$ & 8.49 & 28.29 \\
\hline$\beta$-Tocopherol & 16.07 & 0.43 & 0.9997 & $80.0-800.0$ & 20.03 & 66.77 \\
\hline$\gamma$-Tocopherol & 19.23 & 0.48 & 0.9997 & $80.0-800.0$ & 20.08 & 66.93 \\
\hline$\delta$-Tocopherol & 26.18 & 0.53 & IS & IS & IS & IS \\
\hline
\end{tabular}

IS, internal standard; LOD, limit of detection; LOQ limit of quantification.

tocopherol, calculated from the calibration, multiplied by the concentration of the IS and by the response of the isomer present in the sample divided by the response of the IS in the same injection (quantification by the internal standard method using DataApex 2.4 software).

A fluorescence detector was selected for the quantification purpose since it provided a higher sensitivity than the UV detector. When the contents of the compounds to quantify are low, it is imperative to use a more sensitive detector as fluorescence to achieve more satisfactory results. In order to allow the detection of the four isomers, the best conditions achieved were: $290 \mathrm{~nm}$ for excitation and $330 \mathrm{~nm}$ for emission, gain 100 .

\subsection{Linearity and sensitivity of HPLC analysis}

Table 1 presents the linearity range, limits of detection (LOD) and limits of quantification (LOQ) determined in the present work. After studying the linearity for each compound (11 levels), a 7-level calibration curve was constructed using the peak-area ratio between the three vitamin $\mathrm{E}$ isomers and IS versus concentration ratio between the standards and IS. This calibration curve was injected in five different days and the average obtained was used. The correlation coefficient was always higher than 0.999 for all the compounds.

The limits of detection were calculated as the concentration corresponding to three times the calibration error divided by the slope (Ribani, Bottoli, Collins, Jardim, \& Melo, 2004), and varied from 8.49 to $20.08 \mathrm{ng} / \mathrm{mL}$. The limits of quantification were calculated using the concentration corresponding to 10 times the calibration error divided by the slope (Ribani et al., 2004), and ranged from 28.29 to $66.93 \mathrm{ng} / \mathrm{mL}$.

\subsection{Validation assays}

For the repeatability of the chromatographic method, standards solutions $(80,400$ and $800 \mathrm{ng} / \mathrm{mL})$ were analysed seven times in the same day, while for the reproducibility the standards solutions were analysed three times in five consecutive days. The percentage variation coefficients (CV\%) obtained for the response factor $\left(R_{\mathrm{f}}\right)$ are shown in Table 2 . The chromatographic method proved to be precise for all the isomers being the obtained values very low (CV\% between $0.22 \%$ and $0.91 \%$ ).

Table 3 presents the $\mathrm{CV} \%$ obtained in the validation assays of the extraction methodology. The method used for the mushroom sample proved to be precise and all the values obtained were low (CV\% between $0.27 \%$ and $2.95 \%$ for repeatability and between $2.58 \%$ and $5.02 \%$ for reproducibility). The $\mathrm{CV} \%$ for precision, ranged from $2.35 \%$ to $6.40 \%$. The results demonstrated recovery percentages between $88.3 \%$ and $113.7 \%$, being the lower percentage obtained for $\beta$-tocopherol (Table 4). From analysis of table 4 it can be observed that the recovery percentage is lower for the samples spiked with lower concentration levels; nevertheless, all the values obtained are statistically acceptable. 
Table 2

Repeatability and reproducibility for the response factor of each standard solution in the HPLC analysis

\begin{tabular}{llllllll}
\hline Standard & \multicolumn{3}{l}{ Repeatability CV\% $(n=7)$} & & \multicolumn{4}{c}{ Reproducibility CV\% $(n=15)$} \\
\cline { 2 - 3 } & $\mathrm{S}_{1}$ & $\mathrm{~S}_{2}$ & $\mathrm{~S}_{3}$ & & $\mathrm{~S}_{1}$ & $\mathrm{~S}_{2}$ & $\mathrm{~S}_{3}$ \\
\hline$\alpha$-Tocopherol & 0.51 & 0.65 & 0.29 & & 0.64 & 2.72 & 0.36 \\
$\beta$-Tocopherol & 0.69 & 0.63 & 1.04 & & 0.97 & 4.63 & 2.29 \\
$\gamma$-Tocopherol & 0.22 & 0.59 & 0.94 & & 0.84 & 3.50 & 2.04
\end{tabular}

Standards solutions ( $\left.\mathrm{S}_{1}, 80 \mu \mathrm{g} / \mathrm{mL} ; \mathrm{S}_{2}, 400 \mu \mathrm{g} / \mathrm{mL} ; \mathrm{S}_{3}, 800 \mu \mathrm{g} / \mathrm{mL}\right)$.

Table 3

Method validation parameters obtained using a commercial A. bisporus sample

\begin{tabular}{lllll}
\hline Compound & $\begin{array}{l}\text { Content }(\mathrm{ng} / \mathrm{g}, \\
\text { dry matter) }\end{array}$ & $\begin{array}{l}\text { Repeatability } \\
\text { CV\% }(n=3)\end{array}$ & $\begin{array}{l}\text { Reproducibility } \\
\text { CV\% }(n=15)\end{array}$ & $\begin{array}{l}\text { Precision }^{\text {a }} \\
\text { CV\% }(n=15)\end{array}$ \\
\hline$\alpha$-Tocopherol & $749 \pm 21$ & 2.95 & 5.02 & 6.40 \\
$\beta$-Tocopherol & $1659 \pm 4$ & 0.27 & 2.58 & 2.35 \\
$\gamma$-Tocopherol & n.d. & n.d. & n.d. & n.d. \\
$\delta$-Tocopherol & IS & IS & IS & IS \\
\hline
\end{tabular}

n.d., not detected.

a $\mathrm{CV} \%$ of the results obtained after injection of three sample extractions in five consecutive days.

\section{Table 4}

Recovery percentages obtained after addition to A. bisporus sample of different levels of concentration of each tocopherol and further analysis in triplicate

\begin{tabular}{lllll}
\hline & \multicolumn{3}{l}{$\begin{array}{l}\text { Accuracy (recovery, \%) } \\
\text { Added concentration }(\mathrm{ng} / \mathrm{mL})\end{array}$} & Mean \\
\cline { 2 - 4 } & 80 & 400 & 800 & \\
\hline$\alpha$-Tocopherol & $105.1 \pm 1.1$ & $115.3 \pm 0.5$ & $120.1 \pm 1.0$ & $113.7 \pm 7.6$ \\
$\beta$-Tocopherol & $79.1 \pm 0.8$ & $90.5 \pm 0.9$ & $96.3 \pm 0.6$ & $88.3 \pm 8.7$ \\
$\gamma$-Tocopherol & $97.7 \pm 0.3$ & $112.1 \pm 1.0$ & $119.4 \pm 0.8$ & $109.7 \pm 11$ \\
$\delta$-Tocopherol & - & $99.2 \pm 0.2$ & - & $99.2 \pm 0.2$ \\
\hline
\end{tabular}

Table 5

Tocopherols content (ng/g of dry weight) in mushroom samples

\begin{tabular}{|c|c|c|c|c|c|}
\hline & A. arvensis & A. bisporus & A. romagnesii & A. silvaticus & A. silvicola \\
\hline$\alpha$-Tocopherol & $70 \pm 2 \mathrm{~d}$ & $749 \pm 21 b$ & n.d. & $1301 \pm 13 \mathrm{a}$ & $487 \pm 34 \mathrm{c}$ \\
\hline$\beta$-Tocopherol & $1148 \pm 34 d$ & $1659 \pm 4 b$ & $1289 \pm 15 c$ & $1931 \pm 10 \mathrm{a}$ & $677 \pm 48 \mathrm{e}$ \\
\hline $\begin{array}{l}\text { Total } \\
\text { tocopherols }\end{array}$ & $1218 \pm 37 c$ & $2409 \pm 21 b$ & $1289 \pm 15 c$ & $3232 \pm 3 a$ & $1164 \pm 82 c$ \\
\hline Dry content (\%) & $5.1 \pm 0.8 c$ & $8.2 \pm 0.4 b$ & $12.5 \pm 0.9 a$ & $7.5 \pm 0.6 \mathrm{~b}$ & $5.1 \pm 0.1 \mathrm{c}$ \\
\hline
\end{tabular}

n.d., not detected.

In each row different letters mean significant differences $(p<0.05)$.

\subsection{Tocopherols content in mushroom samples}

Using this methodology, $\alpha$-Toc and $\beta$-Toc were identified and quantified, while $\delta$-Toc, $\gamma$-Toc, and tocotrienols were not detected in the analysed mushroom samples.

The tocopherols content in the five Agaricus sp. samples from Northeast Portugal is presented in Table 5. In all the samples $\beta$-tocopherol was the major compound, ranging from 677 to $1931 \mathrm{ng} / \mathrm{g}$. $\alpha$-Tocopherol was found in all the species with exception for A. romagnesii, while $\delta$ - and $\gamma$-tocopherols were not detected in any of the samples. The results obtained in the analysis of mushroom samples point to the existence of apparent differences in what concerns tocopherols composition among different species. A. silvaticus presented the higher content of tocopherols
(3232 ng/g) while A. silvicola revealed the lower content (1164 ng/g).

Overall, as far as we know, this is the first study reporting an optimization of the determination of tocopherols in mushrooms. It describes a new extraction methodology without saponification step, new chromatographic conditions including fluorescence detection, and simultaneous detection of $\alpha$ and $\beta$-tocopherol isomers. The results obtained demonstrate that the proposed method is sensitive, precise, and accurate allowing the determination of tocopherols.

\section{Acknowledgements}

The authors are grateful to Foundation for Science and Technology (PPCDT/AGR/56661/2004) for financial support of this work.

\section{References}

Amaral, J. A., Casal, S., Torres, D., Seabra, R. M., \& Oliveira, B. P. P. (2005). Simultaneous determination of tocopherols and tocotrienols in hazelnuts by a normal phase liquid chromatographic method. Analytical Sciences, 21, 1545-1548.

Barros, L., Baptista, P., Correia, D. M., Morais, J. S., \& Ferreira, I. C. F. R. (2007). Effects of conservation treatment and cooking on the chemical composition and antioxidant activity of Portuguese wild edible mushrooms. Journal of Agricultural and Food Chemistry, 55, 4781-4788.

Barros, L., Baptista, P., \& Ferreira, I. C. F. R. (2007). Effect of Lactarius piperatus fruiting body maturity stage on antioxidant activity measured by several biochemical assays. Food and Chemical Toxicology, 45, 1731-1737.

Barros, L., Ferreira, M.-J., Queirós, B., Ferreira, I. C. F. R., \& Baptista, P. (2007). Total phenols, ascorbic acid, $\beta$-carotene and lycopene in Portuguese wild edible mushrooms and their antioxidant activities. Food Chemistry, 103, 413-419.

Campbell, S., Stone, W., Whaley, S., \& Krishnan, K. (2003). Development of gamma $(\gamma)$-tocopherol as a colorectal cancer chemopreventive agent. Critical Reviews in Oncology/Hematology, 47, 249-259.

Chun, J., Lee, J., Ye, L., Exler, J., \& Eitenmiller, R. R. (2006). Tocopherol and tocotrienol contents of raw and processed fruits and vegetables in the United States diet. Journal of Food Composition and Analysis, 19, 196-204.

Courtecuisse, R., \& Duhem, B. (1995). In Mushrooms and toadstools of Britain and Europe. London: HarperCollins Publishers.

Elmastas, M., Isildak, O., Turkekul, I., \& Temur, N. (2007). Determination of antioxidant activity and antioxidant compounds in wild edible mushrooms. Journal of Food Composition and Analysis, 20, 337-345.

Ferreira, I. C. F. R., Baptista, P., Vilas-Boas, M., \& Barros, L. (2007). Free-radical scavenging capacity and reducing power of wild edible mushrooms from northeast Portugal: individual cap and stipe activity. Food Chemistry, 100, 1511-1516.

Fukushima, N. S., \& Tsuda, H. (1985). Carcinogenity and modification of the carcinogenic response by BHA, BHT and other antioxidants. Critical Reviews in Toxicology, 15, 109-150.

Halliwell, B., \& Gutteridge, J. M. C. (1999). Free radicals in biology and medicine. United Kingdom: Oxford University Press.

Kamal-Eldin, A., \& Appelqvist, L. (1996). The chemistry and antioxidant properties of tocopherols and tocotrienols. Lipids, 31, 671-701.

Kamal-Eldin, A., Gorgen, S., Peterson, J., \& Lampi, A. (2000). Normal-phase highperformance liquid chromatography of tocopherols and tocotrienols: Comparison of different chromatographic columns. Journal of Chromatography A, 881, 217-227.

Lampi, A., Kataja, L., Kamal-Eldin, A., \& Piironen, V. (1999). Antioxidant activities of $\alpha$ - and $\delta$-tocopherols in the oxidation of rapeseed oil triacylglycerols. Journal of the American Oil Chemists Society, 76, 749-755.

Lindequist, U., Niedermeyer, T. H. J., \& Julich, W.-D. (2005). The pharmacological potential of mushrooms. Evidence-based Complementary and Alternative Medicine (eCAM), 2, 285-299.

Lo, K. M., \& Cheung, P. C. K. (2005). Antioxidant activity of extracts from the fruiting bodies of Agrocybe aegerita var. alba. Food Chemistry, 89, 533-539.

Mau, J.-L., Lin, H.-C., \& Chen, C.-C. (2002). Antioxidant properties of several medicinal mushrooms. Journal of Agricultural and Food Chemistry, 50, 6072-6077.

Mau, J.-L., Lin, H.-C., \& Song, S.-F. (2002). Antioxidant properties of several specialty mushrooms. Food Research International, 35, 519-526.

Mishima, K., Tanaka, T., Pu, F., Egashira, N., Iwasaki, K., Hidaka, R., et al. (2003). Vitamin $\mathrm{E}$ isoforms $\alpha$-tocotrienol and $\gamma$-tocopherol prevent cerebral infarction in mice. Neuroscience Letters, 337, 56-60.

Moser, M. (1983). In Keys to Agarics and Boleti (Polyporales, Boletales, Agaricales, Russulales). London: Roger Phillips.

Ribani, M., Bottoli, C. B. G., Collins, C. H., Jardim, I. C. S. F., \& Melo, L. F. C. (2004). Validação em métodos cromatográficos e electroforéticos. Química Nova, 5, 771-780. 
Ryynanen, M., Lampi, A.-M., Salo-Vaananen, P., Ollilainen, V., \& Piironen, V. (2007). A small-scale sample preparation method with HPLC analysis for determination of tocopherols and tocotrienols in cereals. Journal of Food Composition and Analysis, 17, 749-765.

Sanagi, M. M., See, H. H., Ibrahim, W. A. W., \& Naim, A. A. (2005). Determination of carotene, tocopherols and tocotrienols in residue oil from palm pressed fibe using pressurized liquid extraction-normal phase liquid chromatography. Analytica Chimica Acta, 538, 71-76.

Schwenke, D. C. (2002). Does the lack of tocopherols and tocotrienols put women at increased risk of breast cancer? Journal of Nutritional Biochemistry, 13, 2-20.

Stampfer, M. J., \& Rimm, E. B. (1995). Epidemiologic evidence for vitamin E in prevention of cardiovascular disease. American Journal of Clinical Nutrition, 62 1365-1369.
Stone, W. L., \& Papas, A. M. (1997). Tocopherols and the etiology of colon cancer. Journal of the National Cancer Institute, 89, 1006-1014.

Theriault, A., Chao, J. T., Wang, Q., Gapor, A., \& Adeli, K. (1999). Tocotrienol: a review of its therapeutic potential. Clinical Biochemistry, 32, 309-319.

Tsai, S.-Y., Tsai, H.-L., \& Mau, J.-L. (2007). Antioxidant properties of Agaricus blazei, Agrocybe cylindracea, and Boletus edulis. LWT, 40, 1392-1402.

Turkoglu, A. Duru, M. E. Mercan, N., Kivrak, I., \& Gezer, K. (2007). Antioxidant and antimicrobial activities of Laetiporus sulphurous (Bull.) Murrill. Food Chemistry, $101,267-273$

Yang, J.-H., Lin, H.-C., \& Mau, J.-L. (2002). Antioxidant Properties of several commercial mushrooms. Food Chemistry, 77, 229-235. 